\title{
Kontribusi Koordinasi Mata-Tangan, Kelentukan Pergelangan Tangan, dan Daya Ledak Otot Lengan Terhadap Kemampuan Passing atas Permainan Bola Voli Peserta Ekstrakurikuler
}

\author{
Suparman, Ariana Asri, Haeril \\ Program Studi Pendidikan Jasmani, Kesehatan, dan Rekreasi STKIP YPUP Makassar \\ parman.nebo@gmail.com
}

Received: Januari 2021; Accepted: Februari 2021; Published: Maret 2021

Ed: Maret 2021; 8(1): 49-56

\begin{abstract}
Abstrak
Penelitian ini bertujuan untuk mengetahui kontribusi koordinasi mata-tangan, kelentukan pergelangan tangan, dan daya ledak otot lengan terhadap kemampuan passing atas permainan bola voli peserta ekstrakurikuler putra SMPIT Al-fityan Gowa. Penelitian ini termasuk jenis penelitian deskriptif dengan metode kuantitatif. Populasi adalah seluruh peserta ekstrakurikuler putra SMPIT Al-Fityan Gowa dengan jumlah sampel 30 orang yang di ambil secara random sampling. Teknik analisis data yang di gunakan adalah analisis deskriptif, uji normalitas, uji linearitas, uji regresi sederhana dan uji regresi ganda dengan menggunakan fasilitas komputer melalui program SPSS. Berdasarkan analisis data di peroleh hasil: 1). Ada kontribusi yang signifikan koordinasi mata-tangan terhadap kemampuan passing atas dengan koefisien determinasi (R Square) sebesar 0,506 (50,6\%). 2) Ada kontribusi yang signifikan kelentukan pergelangan tangan terhadap kemampuan passing atas dengan koefisien determinasi (R Square) sebesar 0,447 (44,7\%). 3). Ada kontribusi yang signifikan daya ledak otot lengan terhadap kemampuan passing atas dengan koefisisen determinasi (R Square) sebesar 0,411 (41,1\%) 4). Ada kontribusi yang signifikan secara bersama-sama koordinasi mata-tangan, kelentukan pergelangan tangan, dan daya ledak otot lengan terhadap kemampuan passing atas dengan koefisien diterminasi (R Square) sebesar 0,734 (73,4\%).
\end{abstract}

Kata Kunci: Koordinasi mata-tangan, kelentukan pergelangan tangan, Daya ledak otot lengan, Kemampuan passing atas.

\begin{abstract}
This study aims to determine the contribution of hand-eye coordination, hand muscle flexibility, and arm explosive power to the passing ability of the male extracurricular members of SMPIT Al-fityan Gowa. This research belongs to the type of descriptive research with quantitative methods. The population is all male extracurricular participants of SMPIT Al-Fityan Gowa with a sample of 30 people taken by random sampling. The data analysis technique used is descriptive analysis, normality test, linearity test, simple regression test and multiple regression test using computer facilities through the SPSS program. Based on the analysis of the data obtained the results: 1). There is a significant contribution of eye-hand coordination to the ability to pass over the coefficient of determination ( $R$ Square) of $0.506(50.6 \%)$. 2) There is a significant contribution of flexibility of the superiority of the hand to the ability of passing over with a coefficient of determination ( $R$ Square) of 0.447 $(44.7 \%) .3)$. There is a significant contribution of arm muscle explosive power to the ability to pass over with a coefficient of determination ( $R$ Square) of 0.411 (41.1\%) 4). There is a jointly significant contribution of eye-hand coordination, hand flexibility, and arm muscle explosive power to the upper passing ability with a termination coefficient (R Square) of 0.734 (73.4\%).
\end{abstract}

Keywords: eye-hand coordination 1, hand flexibility 2, arm muscle explosive power 3, upper passing ability. 


\section{PENDAHULUAN}

Menurut kementrian pendidikan dan kebudayaan republik Indonesia (kebudayaan, 2014) mendefinisikan bahwa permainan bola voli merupakan permainan beregu menggunakan bola besar yang dimainankan oleh dua regu saling berhadapan, masing-masing regu enam orang. Permaianan bola voli adalah olahraga yang dimainkan oleh dua tim berlawanan, masing-masing memiliki enam orang pemain (Susanto, 2016). Dalam permainan bola voli ada beberapa teknik dasar yang harus dikuasai yaitu service, passing, block, dan smash. Dari beberapa teknik dasar permaian bola voli, salah satu yang berpengaruh dalam memperoleh suatu kemenangan yaitu passing. Menurut (Hidayat, 2017)) passing merupakan tehnik menerima bola dan mengayunkan kembali kearah yang diinginkan tehnik ini merupakan tehnik dasar dalam suatu permainan bola voli dan harus diketahui oleh mereka yang ingin melakukan permainan tersebut. Adapun passing dalam permainan bola voli ada dua yaitu: passing bawah dan passing atas.

Berdasarkan observasi yang penelti amati disalah satu sekolah swasta yang ada di kabupaten gowa yaitu SMPIT AL-Fityan Gowa. Peneliti melihat kegiatan ekstrakurikuler bola voli, masih banyak kekurangan dalam hal teknik dasar terumata pada saat passing atas. Peneliti menyaksikan pada saat siswa melakukan passing atas perkenaan bola dan jari-jari tangan, posisi badan, pandangan kedepan, cara mengayunkan bola masing kurang tepat. Dengan demikian solusi yang terbaik adalah perlunya dilakukan penelitian ilmiah terhadap permasalahan pukulan passing atas dalam permaian bola voli sehingga dapat menunjang pembinaan dan peningkatan prestasi, seperti keberadaan komponen fisik, teknik, taktik, dan strategi yang diharapkan dapat meningkatkan kemampuan, ketepatan, dan keterampilan pada cabang olahraga bola voli.

Passing atas adalah umpan, dimana pemain yang berada dalam posisi pengunpan untuk menyusun suatu serangan (Rohendi \& Etor, 2018) . Pengunpan menentukan pemain mana yang berada dalam posisi terbaik untuk menyerang dan selanjutnya menggunakan passing atas untuk menempatkan bola kearah dimana penyerang dapat memukul bola dengan agresif keatas jarring. Menurut (Hidayat, 2017) passing atas mengutamakan kekuatan jari-jemari kedua tangan. Seorang pemain hendak melakukan umpan sebelum dilakukan pukulan terakhir atau smash. (Tawakal, 2020) teknik dasar passing atas intinya, bertujuan untuk memberikan atau menyajikan bola kepada teman satu tim, agar bisa melakukan pukulan smash kedaerah lawan. Jadi dapat disimpulkan bahwa seorang pemain bola voli dituntun untuk mahir dalam melakukan passing atas agar bisa memberikan umpan terbaik dari setiap posisi sehingga menciptakan smash yang mematikan.

Komponen fisik yang sangat dibutuhkan dalam melakukan passing atas permainan bola voli adalah koordinasi mata-tangan. Pada saat melakukan pukulan passing atas, koordinasi antara mata dan tangan harus selalu terjadi kontak sehingga bisa memberikan umpan terbaik dari setiap posisi. Sejalan dengan pendapat (Ismaryati, 2018) Koordinasi merupakan hubungan yang harmonis dari hubungan saling pengaruh diantara kelompok-kelompok otot selama melakukan kerja, yang ditunjukkan dengan berbagai tingkat keterampilan. Sedangkan menurut (Halim, 2011) koordinasi adalah kemampuan seseorang mengintegrasikan bermacam-macam gerakan yang berbeda ke dalam pola gerakan. Untuk melakukan ayunan bola yang bisa melambung ke atas untuk bisa dilanjutkan dengan pukulan yang diinginkan dibutuhkan kelentukan pergelangan tangaan (flexibility) adalah kemampuan seseorang dalam menyesuaikan diri untuk segalah aktifitas dengan kelentukan tubuh yang luas (Halim, 2011). Sedangkan Menurut (Hari \& Sukadiyanto, 2010) flexibility adalah keleluasaan gerak, terutama pada otot persendian. Tujuan latihan fleksibilitas adalah agar otot otot sendinya tidak kaku dan dapat bergerak dengan leluasa tanpa gangguan yang berarti. Kemudian untuk melakukan daya dorong yang kuat untuk bisa memberikan umpan pada setiap posisi dibutuhkan daya ledak lengan. Menurut (Rohendi \& Etor, 2018) daya ledak 
merupakan salah satu komponan dasar motorik atau kemampuan yang menunjang penampilan yang efektif dalam olahraga dan permainan. Sedangkan power merupakan suatu rangkaian kerja beberapa umur gerak otot dan meghasilkan daya ledak apabila dua kekuatan otot tersebut bekerja secara bersamaan (Ngatman \& Fitria, 2017).

Penelitian ini bertujuan untuk mengetahui kontribusi koordinasi mata-tangan, kelentukan pergelangan tangan dan daya ledak otot lengan terhadap kemampuan pukulan passing atas permainan bola voli peserta Ekstrakurikuler putra SMPIT Al-Fityan Gowa, baik secara langsung maupun secara bersama-sama.

\section{METODE}

Metode yang digunakan dalam penelitian ini adalah metode penelitian kuantitatif. Metode penelitian kuantitatif dinamakan metode tradisional, karena metode ini sudah cukup lama digunakan sehingga mentradisi sebagai metode untuk penelitian. Metode ini juga disebut sebagai metode ilmiah/scientific karena telah memenuhi kaidah-kaidah ilmiah yaitu konkrit/empiris, obyektif, terukur, rasional, dan sistematis. Menurutnya, Metode ini disebut metode kuantitatif karena data penelitian berupa angka-angka dan analisis menggunakan statistik (Sugiyono, 2018). Penelitian ini menggunakan jenis penelitian deskriptif. Menurut (Juliansyah, 2017) populasi adalah untuk menyebutkan seluruh elemen/anggota dari suatu wilayah yang menjadi sasaran penelitian atau merupakan keseluruhan (universum) dari obyek penelitian. Populasi dari penelitian ini adalah semua peserta ekstrakurikuler putra SMPIT Al-Fityan Gowa yang mengikuti kegiatan ekstrakurikuler permaian bola voli dengan jumlah 30 orang. Sampel yang diambil dalam penelitian ini adalah 30 orang siswa yang diperoleh dengan teknik sampling jenuh.

\section{HASIL DAN PEMBAHASAN}

Hasil dari penelitian ini kemudian dianalisis secara statistik melalui bantuan komputer SPSS 21 dengan taraf signifikan $95 \%$ atau $\alpha=0,05$. Analisis ini dilakukan dengan sistematika sebagai berikut:

1. Uji analisis deskriptif

2. Uji normalitas data dengan menggunakan uji Shapiro-Wilk.

3. Uji analisis inferensial pengujian hipotesis dengan menggunakan analisis regresi sederhana dan analisis regresi ganda.

Analisis data deskriptif dimaksudkan untuk mendapatkan gambaran umum data penelitian, kemudian dilanjutkan dengan pengujian persyaratan analisis yaitu uji normalitas dan linearitas data. Sedangkan analisis data secara inferensial dimaksudkan untuk mendapatkan hasil pengujian hipotesis yang diajukan dalam penelitian ini.

\section{Analisis Deskriptif}

Analisis deskriptif data dari hasil penelitian bertujuan untuk memberikan gambaran secara umum mengenai penyebaran distribusi data koordinasi mata-tangan, kelentukan pergelangan tangan, dan daya ledak otot lengan terhadap kemampuan passing atas permainan bola voli peserta ekstrakurikuler putra SMPIT Al-Fityan Gowa. Deskripsi data dimaksudkan untuk dapat menafsirkan dan memberi makna tentang data tersebut secara berturut-turut seperti pada table berikut ini: 
Tabel 1. Hasil analisis deskriptif tiap variabel

\begin{tabular}{l|c|c|c|c|c|c|c}
\hline & N & Sum & Mean & Stdv & Range & Min. & Max. \\
\hline $\begin{array}{l}\text { Koordinasi } \\
\text { mata-tangan }\end{array}$ & 30 & 481 & 16.03 & 1.426 & 4 & 14 & 18 \\
\hline $\begin{array}{l}\text { Kelentukan } \\
\text { pergelangan } \\
\text { tangan }\end{array}$ & 30 & 1965 & 65.50 & 10.696 & 30 & 50 & 80 \\
\hline $\begin{array}{l}\text { Daya ledak } \\
\text { otot lengan }\end{array}$ & 30 & 10866 & 362.20 & 57.831 & 150 & 290 & 440 \\
\hline $\begin{array}{l}\text { Kemampuan } \\
\text { passing atas }\end{array}$ & 30 & 236 & 7.87 & 1.432 & 4 & 6 & 10 \\
\hline
\end{tabular}

\section{Uji Normalitas Data}

Salah satu asumsi yang harus dipenuhi agar uji parametrik dapat digunakan dalam penelitian adalah data harus mengikuti sebaran normal, maka dilakukan uji normalitas data. Pengujian normalitas data dapat dilakukan untuk mengetahui apakah data yang diperoleh pada hasil penelitian berada pada sebaran normal. Pengujian normalitas data dapat dilakukan dengan uji Shapiro-Wilk.

\section{Tabel 2. Hasil Uji Normalitas}

\begin{tabular}{l|c|c|c}
\multicolumn{1}{c}{ Variabel } & P & $\boldsymbol{\alpha}$ & Ket \\
\hline Koordinasi mata-tangan & 0,500 & 0,05 & Normal \\
\hline Kelentukan pergelangan tangan & 0,544 & 0,05 & Normal \\
\hline Daya ledak otot lengan & 0,179 & 0,05 & Normal \\
\hline Kemampuan passing atas & 0,420 & 0,05 & Normal \\
\hline
\end{tabular}

\section{Hasil Pengujian Hipotesis}

Karena data penelitian ini mengikuti sebaran normal dan memiliki hubungan atau linear, maka untuk menguji hipotesis penelitian ini digunakan analisis statistik parametrik.

a. Hasil pengujian kontribusi koordinasi mata-tangan terhadap kemampuan passing atas permainan bola voli

Tabel 3. Hasil Uji Hipotesis melalui Analisis Regresi Sederhana

\begin{tabular}{|c|c|c|c|c|}
\hline Variabel & $\mathbf{r}$ & $\mathbf{R}$ & $\mathbf{P}$ & Ket \\
\hline $\begin{array}{l}\text { Kontribusi Koordinasi } \\
\text { mata-tangan }\left(X_{1}\right) \\
\text { terhadap Kemampuan } \\
\text { Passing atas }(Y)\end{array}$ & 0,712 & 0,506 & 0,000 & Sig \\
\hline
\end{tabular}


b. Hasil pengujian kontribusi kelentukan pergelangan tangan terhadap kemampuan passing atas permainan bola voli.

Tabel 4. Hasil Uji Hipotesis melalui Analisis Regresi Sederhana

\begin{tabular}{l|c|c|c|c} 
Variabel & $\mathbf{r}$ & $\mathbf{R}$ & $\mathbf{P}$ & Ket \\
$\begin{array}{l}\text { Kontribusi Kelentukan } \\
\text { pergelangan tangan } \\
\left(\mathbf{X}_{2}\right) \text { terhadap }\end{array}$ & 0,669 & 0,447 & 0,000 & Sig \\
$\begin{array}{l}\text { Kemampuan passing } \\
\text { atas (Y) }\end{array}$ & & & & \\
\hline
\end{tabular}

c. Hasil pengujian kontribusi daya ledak otot lengan terhadap kemampuan passing atas permainan bola voli.

Tabel 5. Hasil Uji Hipotesis melalui Analisis Regresi Sederhana

\begin{tabular}{l|c|c|c|c}
\multicolumn{1}{c|}{ Variabel } & $\mathbf{r}$ & $\mathbf{R}$ & $\mathbf{P}$ & Ket \\
\hline $\begin{array}{l}\text { Kontribusi daya ledak } \\
\text { otot lengan (X3) } \\
\text { terhadap Kemampuan } \\
\text { passing atas(Y) }\end{array}$ & 0,641 & 0,411 & 0,000 & Sig \\
\hline
\end{tabular}

d. Hasil pengujian kontribusi koordinasi mata-tangan, kelentukan pergelangan tangan, dan daya ledak otot lengan secara bersama-sama terhadap kemampuan passing atas permainan bola voli

\begin{tabular}{l|c|c|c|c}
\multicolumn{4}{c}{ Tabel 6. Hasil Uji Hipotesis melalui Analisis Regresi Ganda } \\
Variabel & $\mathbf{r}$ & $\mathbf{R}$ & $\mathbf{P}$ & Ket \\
\hline $\begin{array}{l}\text { Kontribusi Koordinasi } \\
\text { mata-tangan }\left(\mathbf{X}_{1}\right),\end{array}$ & & & & \\
$\begin{array}{l}\text { kelentukan pergelangan } \\
\text { tangan }\left(\mathbf{X}_{2}\right) \text {, dan daya } \\
\text { ledak otot lengan }\left(\mathbf{X}_{3}\right) \\
\text { terhadap Kemampuan } \\
\text { passing atas }(\mathbf{Y})\end{array}$ & 0,857 & 0,734 & 0,000 & Sig \\
\hline
\end{tabular}

Dari hasil pengujian hipotesis pertama dapat dikemukakan bahwa ada kontribusi yang signifikan koordinasi mata-tangan terhadap kemampuan passing atas permainan bola voli peserta ekstrakurikuler putra SMPIT Al-Fityan Gowa. Hal ini dapat diketahui dari hasil analisis diperoleh nilai koefisien korelasi $(r)=0,712$ dan $\mathrm{p}$-value $=0,000<0,05$. Hal ini berarti H0 ditolak dan H1 diterima. Dengan demikian, koefisien korelasi berarti atau signifikan. Sedangkan pada analisis koefisien determinasi ( $\mathrm{R}$ Square) diperoleh nilai sebesar 0,506 yang berarti 50,6\% dari variabel kemampuan passing atas permainan bola voli (Y) disebabkan oleh koordinasi mata-tangan (X1). Hal ini berarti 50,6\% data koordinasi mata-tangan (X1) memberikan kontribusi langsung terhadap 
kemampuan passing atas permainan bola voli (Y). Apabila hasil penelitian ini dikaitkan dengan pendapat (Halim, 2011) Koordinasi adalah suatu kemampuan biomotorik yang sangat kompleks, koordinasi erat hubungannya dengan kecepatan, kelincahan, kekuatan, daya tahan dan fleksibilitas, dan semuanya yang menyumbang terpadu didalam koordinasi gerak oleh karena itu satu sama lainnya memiliki hubungan yang sangat erat. Maka dapat disimpulkan untuk melakukan passing atas, koordinasi antara mata dan tangan harus selalu terjalin kontak sehingga bisa memberikan umpan terbaik dari setiap posisi.

Dari hasil pengujian hipotesis kedua dapat dikemukakan bahwa ada kontribusi yang signifikan kelentukan pergelangan tangan terhadap kemampuan passing atas permainan bola voli peserta ekstrakurikuler SMPIT Al-Fityan Gowa. Hal ini dapat diketahui dari hasil analisis diperoleh nilai koefisien korelasi $(r)=0,669$ dan $\mathrm{p}$-value $=0,000<0,05$. Hal ini berarti H0 ditolak dan H1 diterima. Dengan demikian, koefisien korelasi berarti atau signifikan. Sedangkan pada analisis koefisien determinasi (R Square) diperoleh nilai sebesar 0,447 yang berarti $44,7 \%$ dari variabel kemampuan passing atas (Y) disebabkan oleh kelentukan pergelangan tangan (X2). Hal ini berarti $44,7 \%$ data kelentukan pergelangan tangan (X2) memberikan kontribusi langsung terhadap kemampuan passing atas permainan bola voli (Y). Apabila hasil penelitian ini dikaitkan dengan pendapat (Widiastuti, Tes dan Pengukuran Olahraga, 2019) kelentukan adalah kemampuan sendi untuk melakukan gerakan dalam ruang gerak sendi secara maksimal. Sedangkan menurut (Albertus \& Muhammad , 2015) kelentukan adalah kemampuan menggerakkan tubuh atau bagianbagiannya seluas mungkin tanpa terjadi ketegangan sendi dan cedera otot. Secara sederhana dapat diartikan bahwa kelentukan adalah luas gerakan dari suatu sendi dan dapat pula diartikan bahwa kelentukan adalah kapasitas untuk bergerak dalam ruang gerak sendi. Maka dapat disimpulkan untuk melakukan passing atas, unsur kelentukan pergelangan tangan berperan penting dalam melakukan dorongan dengan jari-jari tangan dengan cara mengeper sehingga bisa memberikan umpan secara varabol.

Dari hasil pengujian hipotesis ke tiga dapat dikemukakan bahwa ada kontribusi yang signifikan daya ledak otot lengan terhadap kemampuan passing atas permainan bola voli peserta ekstrakurikuler putra SMPIT Al-fityan Gowa. Hal ini dapat diketahui dari hasil analisis diperoleh nilai koefisien korelasi $(r)=0,641$ dan $\mathrm{p}$-value $=0,000<0,05$. Hal ini berarti $\mathrm{H} 0$ ditolak dan $\mathrm{H} 1$ diterima. Dengan demikian, koefisien korelasi berarti atau signifikan. Sedangkan pada analisis koefisien determinasi ( $\mathrm{R}$ Square) diperoleh nilai sebesar 0,411 yang berarti 41, 1\% dari variabel kemampuan passing atas permainan tenis meja (Y) disebabkan oleh daya ledak otot lengan (X3). Hal ini berarti $41,1 \%$ data daya ledak otot lengan (X3) memberikan kontribusi langsung terhadap kemampuan passing atas permainan bola voli (Y). Apabila hasil penelitian ini dikaitkan dengan pendapat (Rohendi \& Etor, 2018) Daya ledak adalah kemampuan syaraf otot untuk mengatasi tahanan dan kontraksi otot yang sangat cepat. Jadi dapat disimpulkan bahwa ketika seorang pemain memiliki daya ledak otot lengan yang baik maka dalam melakukan passing atas dengan cepat dan tepat pada posisi yang akan diberikan umpan untuk dilanjutkan pada pukulan smash.

Dari hasil pengujian hipotesis ke empat dapat dikemukakan bahwa ada kontribusi yang signifikan koordinasi mata-tangan, kelentukan pergelangan tangan dan daya ledak otot lengan terhadap kemampuan passing atas permainan bola voli peserta ekstrakurikuler SMPIT Al-Fityan Gowa. Hal ini dapat diketahui dari hasil analisis diperoleh nilai koefisien korelasi $(r)=0,857$ dan p-value $=0,000<0,05$. Hal ini berarti H0 ditolak dan H1 diterima. Dengan demikian, koefisien korelasi berarti atau signifikan. Sedangkan pada analisis koefisien determinasi (R Square) diperoleh nilai sebesar 0,734 yang berarti $0,73,4 \%$ dari variabel kemampuan passing atas permainan bola voli (Y) disebabkan oleh koordinasi mata-tangan, kelentukan pergelangan tangan 
dan daya ledak otot lengan (X4). Hal ini berarti 73,4\% data koordinasi mata-tangan (X1), kelentukan pergelangan tangan (X2) dan daya ledak otot lengan (X3) secara bersama-sama memberikan kontribusi langsung terhadap kemampuan passing atas permainan bola voli (Y) dan sisanya $26,6 \%$ atau $(100 \%-73,4 \%)=26,6 \%)$. Disebabkan oleh faktor-faktor lain yang tidak temasuk dalam penelitian ini. Apabila hasil penelitian ini dikaitkan dengan pendapat (Hidayat, 2017) passing atas yaitu posisi badan pada teknik passing atas kedua kaki harus sedikit ditekuk untuk membantu menghasilkan lontaran secara baik. Kedua tangan berada disamping dengan posisi telapak tangan membuka. Pada saat bola datang, telapak tangan mengahdap ke arah bola dan menyentuhnya dengan ujung jari. Proses ini harus dilakukan dengan cepat. Setelah menyentuh ujung jari, buatlah ayunan secara serempak mulai dari kedua kaki dan tangan. Arah bola melambung ke atas untuk bisa melanjutkan dengan pukulan yang diinginkan. Sedangkan menurut (Rohendi \& Etor, 2018) passing atas adalah umpan, dimana pemain yang berada dalam posisi pengunpan untuk menyusun suatu serangan. Pengunpan menentukan pemain mana yang berada dalam posisi terbaik untuk menyerang dan selanjutnya menggunakan passing atas untuk menempatkan bola kearah dimana penyerang dapat memukul bola dengan agresif keatas jaring. Jadi dapat disimpulkan bahwa untuk melancarkan serangan smash yang keras seorang pemain bola voli dituntut untuk mahir dalam melakukan passing atas terutama pada posisi tosser, karena harus bisa memberikan umpan yang memanjakan pemain lain untuk melakukan smash secara sempurna.

\section{KESIMPULAN}

Berdasarkan hasil penelitian dan pembahasan yang telah dikemukakan, maka dapat ditarik kesimpulan bahwa koordinasi mata-tangan, kelentukan pergelangan tangan, dan daya ledak otot lengan memiliki kontribusi yang signifikan terhadap kemampuan passing atas permainan bola voli baik secara langsung maupun secara bersama-sama.

Saran peneliti adalah dalam memilih atlet yang akan dilatih sebaiknya, guru pendidikan jasmani, dosen, pelatih dan pembina olahraga selalu memperhatikan unsur komponen fisik yang berperan seperti koordinasi mata-tangan, kelentukan pergelangan tangan, dan daya ledak otot lengan pada olahraga bola voli khususnya dalam usaha meningkatkan kemampuan passing atas. Kepada rekan-rekan peneliti di sarankan untuk melakukan penelitian lanjutan dengan cakupan yang luas dan melihat kemungkinan adanya variabel lain yang juga memiliki kontribusi yang signifikan terhadap olahraga permainan bola voli.

\section{DAFTAR PUSTAKA}

Albertus, F., \& Muhammad , M. (2015). Tes \& Pengukuran dalam Olahraga. Yogyakarta: CV ANDI OFFSET.

Halim, N. I. (2011). Tes dan Pengukuran Kesegaran Jasmani. Makassar: Badan Penerbit UNM Makassar.

Hari, A., \& Sukadiyanto. (2010). Penjasorkes. Bogor: Quandra.

Hidayat, W. (2017). Buku Pintar Bola Voli. Jakarta: Anugrah.

Ismaryati. (2018). Tes da Pengukuran Olahraga. Jawa Tengah: UNS Press.

Juliansyah, N. (2017). Metodologi Penelitian Skripsi, Tesis, Disertasi, \& Karya Ilmiah. Jakarta:

PT. Fajar Interpratama Mandiri.

kebudayaan, K. P. (2014). Pendidikan Jasmani Olahraga dan Kesehatan. Jakarta: Kementrian Pendidikan dan Kebudayaan. 
Ngatman, \& Fitria, D. (2017). Tes dan Pengukuran untuk Evaluasi Pendidikan Jasmani dan Olahraga. Yogyakarta: Fadilatama.

Rohendi , A., \& Etor, S. (2018). Metode Penelitian dan pembelajaran bola voli. Bandung: Alfabeta. Sugiyono. (2018). Metode Penelitian Kuantitatif, Kualitatif, dan R\&D. Bandung: Alfabeta.

Susanto, T. (2016). Buku Pintar Olahraga. Yogyakarta: Pustaka Baru Press.

Tawakal, I. (2020). Buku Jago Bola Voli. Tangerang selatan: Ilmu Cemerlang Group.

Widiastuti. (2011). Tes dan Pengukuran Olahraga. Jakarta: PT Bumi Timur Jaya.

Widiastuti. (2017). Tes dan Pengukuran Olahraga. Jakarta: PT Rajagrafindo Persada.

Widiastuti. (2019). Tes dan Pengukuran Olahraga. Jakarta: Rajawali Press., 